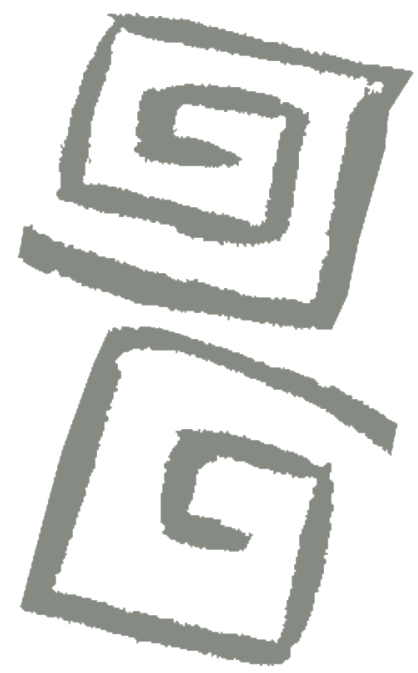

\title{
De "culpables" a "víctimas": expansión y profesionalización del sistema de salud en la provincia Mendoza a fines del siglo XIX y principios del XX
}

\author{
From "culprits" to "victims:" the expansion and \\ professionalization of the healthcare system in the province \\ of Mendoza in the late nineteenth and early twentieth \\ century
}

Natalia Luis' ${ }^{1}$, Rosana Aguerregaray Castilgione ${ }^{2}$

${ }^{1}$ Autora de correspondencia. Doctora en Historia. Instituto de Ciencias Humanas, Sociales y Ambientales (INCIHUSA), Centro Científico Tecnológico Mendoza, unidad ejecutora del Consejo Nacional de Investigaciones Científicas y Técnicas (CONICET). Mendoza, Argentina. $\square$ (iD

${ }^{2}$ Doctora en Historia. Instituto de Ciencias Humanas, Sociales y Ambientales (INCIHUSA), Centro Científico Tecnológico Mendoza, unidad ejecutora del Consejo Nacional de Investigaciones Científicas y Técnicas (CONICET). Mendoza, Argentina. $\triangle$ iD
RESUMEN Entre fines del siglo XIX y comienzos del XX, la provincia de Mendoza presentaba un estado sanitario marcado por el crecimiento demográfico y urbanístico, la escasez de los servicios públicos y la destrucción de la antigua ciudad colonial como consecuencia del terremoto de 1861, lo que propiciaba un ambiente favorable para el desarrollo de diversas enfermedades infectocontagiosas. El objetivo de este artículo es indagar cómo se fue profesionalizando y expandiendo el sistema de salud en la provincia de Mendoza a fines del siglo XIX e inicios del XX, y cómo esos factores, junto con las representaciones sobre la enfermedad que predominaban en el discurso de la elite gobernante, incidieron en las políticas públicas para combatir las dolencias de la época. Para ello se consultaron diversos documentos escritos y fotográficos que permitieron analizar las modificaciones del discurso y las políticas públicas implementadas.

PALABRAS CLAVES Epidemias; Enfermedades Transmisibles; Sistemas de Salud; Política de Salud; Argentina.

ABSTRACT From the late 19th century to the beginning of the 20th, the province of
Mendoza presented problematic sanitary conditions due to rapid demographic and urban
growth, the scarcity of public services, and the poor state of the old colonial city (destroyed
by the 1861 earthquake), which facilitated the spread of various infectious diseases.
The objective of this article is to inquire into the ways in which the healthcare system
in the province of Mendoza both expanded and became increasingly professionalized
from the late 19th to early 20th century. We explore how these factors, along with the
predominant social representations of disease that permeated the discourses of governing
elites, influenced public policy aimed at combating the diseases of the time. To that end,
we consulted a wide range of written documents and photographic material that allowed
us to analyze changes in discourse as well as public policy. KEY WORDS Epidemics; Communicable Diseases; Health Systems; Health Policy; Argentina. 


\section{INTRODUCCIÓN}

A fines del siglo XIX y principios del XX, el estado sanitario de la provincia de Mendoza estaba marcado por la sucesión de numerosas epidemias, como el cólera, la viruela, la difteria, la escarlatina, "engripado", tuberculosis. Esta situación crítica se vinculó con un acentuado crecimiento demográfico y urbanístico producido desde 1880 , en un marco de escasez de medios materiales necesarios para intervenir sobre el entorno sanitario de la ciudad, provocando los primeros desajustes de un ambiente urbano cada vez más vulnerable. Particularmente, impactó la llegada del ferrocarril, el crecimiento de la inmigración y, con ella, el establecimiento de conventillos y casas de alojamiento que carecían de condiciones básicas de higiene; de hecho, no es casual que el primer caso de cólera se registrase en este tipo de viviendas, en el verano de 1886.

A ello se sumaron las condiciones de la antigua ciudad colonial, destruida tras el terremoto de 1861. La presencia de sus propios escombros y la falta de limpieza e higiene la convertían en un posible foco de infección para toda la población mendocina. Por su parte, la escasez de los servicios, como el alumbrado público, la nivelación de las calles y, fundamentalmente, el agua corriente domiciliara y el tendido de la red cloacal agravaron la situación.

No obstante, durante este periodo el Estado comenzó a intervenir y a incrementar sus funciones en materia social, creando instituciones gubernamentales encargadas de velar por la salubridad de la población y, al mismo tiempo, se fue profesionalizando el campo disciplinar de la salud y se reglamentó el ejercicio de las actividades curativas.

En este contexto, el objetivo de este artículo es indagar cómo se fue profesionalizando y expandiendo el sistema de salud en la provincia de Mendoza a fines del siglo XIX e inicios del XX; y cómo estos factores junto con las representaciones sobre la enfermedad que predominaban en el discurso de la elite gobernante incidieron en las políticas públicas para combatir las dolencias de la época. Se parte del concepto de elite desarrollado por Losada ${ }^{(1)}$, quien considera que la alta sociedad porteña de la Belle Époque constituyó un "actor colectivo", en tanto compartían una forma y estilo de vida que les daba cohesión y les permitía identificarse como grupo social de pertenencia. Este estaba caracterizado por la heterogeneidad y su punto de contacto estaba dado a través de la vida social y cultural de los sujetos, aun cuando su poder político, económico y su sofisticación cultural podían variar. Se considera que los altos cargos políticos estaban dirigidos por miembros de esta elite, que excedía el ámbito político.

Partimos del supuesto de que uno de los factores que influyó en el discurso de los gobernantes, a lo largo del siglo XX, fue la profesionalización del campo de la salud, que implicó que las medidas ya no se aplicaran de forma exhaustiva sobre los sectores de menor poder adquisitivo, sino sobre la población en general.

Esto estuvo íntimamente relacionado, además, con las modificaciones a nivel político. Luego de un largo periodo de orden conservador signado por el fraude electoral, entre fines del siglo XIX y comienzos del XX nuevas olas de radicalización transformaron las prácticas políticas en Latinoamérica. En las ciudades comenzaron a formarse nuevas agrupaciones políticas -liberales avanzados, radicales, socialistas- cuya composición y forma de actuar quebraban la paz de los "acuerdos entre caballeros". Principalmente, en el decenio 1910-1920, Latinoamérica presenció una breve pero intensa oleada de democracia liberal que, en Argentina, nació de la crisis de 1890 y tomó cuerpo con la Unión Cívica Radical (UCR) bajo el liderazgo de Hipólito Yrigoyen ${ }^{(2,3,4)}$. Y, en ese contexto, fue particularmente importante la Ley $8871 \mathrm{o}$ Ley Sáenz Peña de 1912, que implicó la obligatoriedad y el secreto del voto y la representación de la minoría, permitiendo elecciones más transparentes que trajeron aparejado un proceso de democratización política ${ }^{(5,6)}$. Así, las elecciones de 1916 llevaron a la UCR al gobierno nacional, agrupación que había 
cuestionado el orden ideológico y político establecido desde 1880, y había propuesto modificar diversos aspectos de la vida política, social, económica e institucional del país ${ }^{(7)}$. Esta victoria del radicalismo se reiteró también en Mendoza, en las elecciones provinciales de 1917 que llevaron a José Néstor Lencinas a la gobernación.

A partir de la consolidación de la estructura partidaria radical y su victoria nacional en el año 1916 y, a nivel local, en 1917, el radicalismo fue construyendo una identidad política y cultural que presentó como sus principales enemigos a los miembros de la "oligarquía"(8). El régimen oligárquico cedió terreno a favor de la democratización, sobre la base del liderazgo personalista o mesiánico de Lencinas. Este referente provincial del radicalismo lideró lo que ciertos autores Ilaman "populismo mendocino(9,10,11). El discurso antioligárquico y el contacto con las masas se tradujo en las políticas públicas propuestas e implementadas por los dirigentes, que incluyeron la participación de sectores de clase media y baja en ámbitos que antes eran exclusividad de las elites.

Para llevar a cabo el trabajo utilizamos un corpus documental integrado por notas y fotografías de la prensa y revistas locales, normativas sancionadas por el Estado provincial, informes técnicos médicos y de salubridad pública que fueron realizados durante y después de las pestes. Por medio de estos documentos es posible analizar el discurso de la elite gobernante, las políticas públicas y los tratamientos que se implementaron durante la época de los brotes y su aplicación sobre la sociedad.

\section{ESTADO SANITARIO PROVINCIAL ENTRE FINES DEL SIGLO XIX Y PRINCIPIOS DEL SIGLO XX}

Durante fines del siglo XIX y principios del XX, las enfermedades devinieron en un problema social, ya que se las comenzó a vincular con otras urgencias, por lo que se convirtió en una necesidad primordial tratar de evitarlas y gestionarlas por medio de políticas públicas. De este modo, la higiene adquirió un rol fundamental, tanto en sus "contenidos preventivos como disciplinadores" ${ }^{\prime(12)}$. A lo largo de ese periodo, la ciudad y la provincia de Mendoza fue víctima de numerosas enfermedades, entre ellas: cólera, viruela, difteria, escarlatina, bocio, "engripado" y tuberculosis (Tabla 1 y Tabla 2). Esta situación crítica se vinculó con un acentuado crecimiento demográfico y urbanístico producido desde 1880, cuando simultáneamente no se disponían de los medios materiales necesarios para propiciar en la ciudad un entorno sanitario para su prevención y tratamiento, provocando los "primeros desajustes de un ambiente urbano cada vez más vulnerable donde las epidemias no distinguían entre ricos y pobres"(13).

Al respecto, Juan Manuel Cerdá explica cómo la incorporación de un número significativo de inmigrantes a finales del siglo XIX, junto a un proceso de reorganización productiva asociado al desarrollo de la industria vitivinícola implicó cambios en las relaciones sociales y en las condiciones de vida de amplios sectores de la población mendocina. Particularmente, señala que los trabajadores pasaron por períodos de alta precariedad e inestabilidad en sus trabajos, aspecto que afectó directamente sus condiciones de vida ${ }^{(22,23)}$.

A ello se sumaron las condiciones en las que se encontraba la antigua ciudad colonial que, tras el terremoto de 1861, sufrió incendios, inundaciones y saqueos, con lo cual la ciudad se vio totalmente destruida, con una gran pérdida material y humana. Lo único que se mantuvo en pie fue una iglesia de los jesuitas (actualmente denominadas ruinas de San Francisco) y una de San Agustín, ubicadas en torno a la plaza. El resto de las edificaciones se vieron sumergidas en sus propios escombros de adobe y paja, debido a que se emplearon principalmente estos materiales para su construcción; no en vano se llamó el "Barrio de las Ruinas"(24). A partir de entonces, este sector comenzó a denominarse la "ciudad vieja", y este corte abrupto permitió la conformación de una "nueva ciudad", con un planteamiento "moderno y progresista", ubicada en la zona de San Nicolás. La antigua 
Tabla 1. Número y distribución porcentual de las muertes totales y por causas infecciosas seleccionadas. Ciudad de Mendoza, Argentina, 1886-1899.

\begin{tabular}{|c|c|c|c|c|}
\hline Año & $\begin{array}{l}\text { Total de } \\
\text { muertes }\end{array}$ & Principal enfermedad infectocontagiosa & $\begin{array}{c}\text { Número de muertes } \\
\text { por enfermedades } \\
\text { infectocontagiosas }\end{array}$ & $\begin{array}{c}\text { Porcentaje del total } \\
\text { de muertes }\end{array}$ \\
\hline \multirow{3}{*}{1886} & \multirow{3}{*}{1.586} & Cólera & $665^{*}$ & 42,0 \\
\hline & & Otras enfermedades infectocontagiosas & 161 & 10,1 \\
\hline & & Otras causas & $760^{*}$ & 47,9 \\
\hline \multirow{3}{*}{1887} & \multirow{3}{*}{1.002} & Cólera & $125^{*}$ & 12,5 \\
\hline & & Otras enfermedades infectocontagiosas & 211 & 21,0 \\
\hline & & Otras causas & $666^{*}$ & 66,5 \\
\hline \multirow{2}{*}{1888} & \multirow{2}{*}{1.271} & Sarampión, tuberculosis, coqueluche, viruela & 356 & 28,0 \\
\hline & & Otras causas & 915 & 72,0 \\
\hline \multirow{2}{*}{1889} & \multirow{2}{*}{1.772} & Viruela & 771 & 43,5 \\
\hline & & Otras causas & 1.001 & 56,5 \\
\hline \multirow{2}{*}{1890} & \multirow{2}{*}{1.250} & Viruela, difteria, tuberculosis, fiebre tifoidea & 330 & 26,4 \\
\hline & & Otras causas & 920 & 73,6 \\
\hline \multirow{2}{*}{1891} & \multirow{2}{*}{1.297} & Difteria & 504 & 38,9 \\
\hline & & Otras causas & 793 & 61.1 \\
\hline \multirow{2}{*}{1892} & \multirow{2}{*}{1.440} & Difteria & 442 & 30,7 \\
\hline & & Otras causas & 998 & 69,3 \\
\hline \multirow{2}{*}{1894} & \multirow{2}{*}{1.295} & Difteria & 325 & 25,1 \\
\hline & & Otras causas & 970 & 74,9 \\
\hline \multirow{2}{*}{1895} & \multirow{2}{*}{1.496} & Difteria, escarlatina & 461 & 30,8 \\
\hline & & Otras causas & 1.035 & 69,2 \\
\hline
\end{tabular}

ciudad perdió sus usos administrativos y políticos. Se instaló el matadero público (en el sitio donde se encontraba el destruido cabildo), el hospital, el lazareto, los conventillos, los prostíbulos. No contaba ni con calles empedradas ni arboladas, así como tampoco con agua corriente ni cloacas, a pesar de albergar una gran cantidad de población, en especial de los sectores populares ${ }^{(24)}$. Durante dos décadas, la antigua ciudad mantuvo esas condiciones, y fue uno de los motivos por el que la administración municipal pretendía que los sujetos que allí vivían se trasladaran al nuevo sector. No obstante, los grupos populares no contaban con los recursos económicos para construir nuevas viviendas.
Por su parte, en la ciudad nueva se planteó un trazado que tenía como centro una plaza-parque (constituida por cuatro manzanas), denominada "Independencia", equidistante y en línea diagonal a esta se emplazaron cuatro plazas-parques más. En torno a este espacio principal se propuso ubicar la Casa de Gobierno, la Casa de Justicia, la Iglesia matriz, la cárcel y la policía. Albergaba todas las reparticiones y oficinas públicas provinciales y municipales. A su vez, se desplazaron hacia este sector los grupos de mayor poder adquisitivo y, posteriormente, se edificó un parque artificial. Podemos observar que en ese entonces había dos sectores bien diferenciados en el interior de la ciudad: por un lado, la "vieja ciudad 
Tabla 2. principales enfermedades infectocontagiosas en la provincia de Mendoza, Argentina, entre 1914 y 1927.

\begin{tabular}{|c|c|c|c|c|}
\hline \multirow{2}{*}{ Año } & \multirow{2}{*}{$\begin{array}{l}\text { Total de } \\
\text { muertes }\end{array}$} & \multirow{2}{*}{ Causas } & \multicolumn{2}{|c|}{ Muertes } \\
\hline & & & $\mathrm{n}$ & $\%$ \\
\hline \multirow{2}{*}{1914} & \multirow{2}{*}{6.661} & Difteria, Tifoidea & 279 & 4,2 \\
\hline & & Otras causas & 6.382 & 95,8 \\
\hline \multirow{4}{*}{1918} & \multirow{4}{*}{7.261} & Tuberculosis & 531 & 7,3 \\
\hline & & Gripe & 170 & 2,3 \\
\hline & & Otras enfermedades infectocontagiosas & 587 & 8,1 \\
\hline & & Otras causas & 6.730 & 92,7 \\
\hline \multirow{4}{*}{1919} & \multirow{4}{*}{7.883} & Tuberculosis & 555 & 7,0 \\
\hline & & Gripe & 940 & 11,9 \\
\hline & & Otras enfermedades infectocontagiosas & 513 & 6,5 \\
\hline & & Otras causas & 5.875 & 74,5 \\
\hline \multirow{4}{*}{1920} & \multirow{4}{*}{6.578} & Tuberculosis & 405 & 6,2 \\
\hline & & Gripe & 82 & 1,2 \\
\hline & & Otras enfermedades infectocontagiosas & 449 & 6,8 \\
\hline & & Otras causas & 5.642 & 85,8 \\
\hline \multirow{4}{*}{1921} & \multirow{4}{*}{6.878} & Tuberculosis & 443 & 6,4 \\
\hline & & Gripe & 356 & 5,2 \\
\hline & & Otras enfermedades infectocontagiosas & 490 & 7,1 \\
\hline & & Otras causas & 5.589 & 81,3 \\
\hline \multirow{4}{*}{1922} & \multirow{4}{*}{6.591} & Tuberculosis & 497 & 7,5 \\
\hline & & Gripe & 47 & 0,7 \\
\hline & & Otras enfermedades infectocontagiosas & 497 & 7,5 \\
\hline & & Otras causas & 5.550 & 84,2 \\
\hline \multirow{4}{*}{1923} & \multirow{4}{*}{7.647} & Tuberculosis & 462 & 6,0 \\
\hline & & Gripe & 478 & 6,3 \\
\hline & & Otras enfermedades infectocontagiosas & 623 & 8,1 \\
\hline & & Otras causas & 6.084 & 79,6 \\
\hline \multirow{4}{*}{1924} & \multirow{4}{*}{6.785} & Tuberculosis & 399 & 5,9 \\
\hline & & Gripe & 92 & 1,4 \\
\hline & & Otras enfermedades infectocontagiosas & 462 & 6,8 \\
\hline & & Otras causas & 5.832 & 85,9 \\
\hline \multirow{4}{*}{1925} & \multirow{4}{*}{6.538} & Tuberculosis & 433 & 6,6 \\
\hline & & Gripe & 116 & 1,8 \\
\hline & & Otras enfermedades infectocontagiosas & 424 & 6,5 \\
\hline & & Otras causas & 5.565 & 85,1 \\
\hline \multirow{4}{*}{1926} & \multirow{4}{*}{6.477} & Tuberculosis & 419 & 6,5 \\
\hline & & Gripe & 74 & 1,1 \\
\hline & & Otras enfermedades infectocontagiosas & 606 & 9,4 \\
\hline & & Otras causas & 5.378 & 83,0 \\
\hline \multirow{4}{*}{1927} & & Tuberculosis & 416 & 6,1 \\
\hline & 6830 & Gripe & 55 & 0,8 \\
\hline & & Otras enfermedades infectocontagiosas & 517 & 7,6 \\
\hline & & Otras causas & 5.842 & 85,5 \\
\hline
\end{tabular}

Fuente: Elaboración propia basada en datos de los anuarios estadísticos publicados entre 1914 y $1928^{(15,16,17,18,19,20)}$ y el estudio de Juan Antonio Orfila, a cargo de la Dirección General de Salubridad ${ }^{(21)}$. 
colonial" contenedora de todos aquellos elementos considerados "peligrosos" $y$, por otro lado, la "nueva ciudad moderna", vinculada a los nuevos espacios de sociabilidad de los sectores de mayor poder adquisitivo.

La escasez de servicios como el alumbrado público, la nivelación de las calles y, fundamentalmente, el agua corriente domiciliara agravaron la situación, del mismo modo que lo hicieron la llegada del ferrocarril, el crecimiento de la inmigración y, con ella, los conventillos ${ }^{(24)}$. De estas cuestiones, el principal problema sanitario que debía enfrentar la provincia era la escasez de agua potable, la cual era distribuida por medio de una red hídrica de canales que se ramificaban en una serie de acequias que atravesaban las manzanas. En 1876 se habían realizado los primeros trabajos sistemáticos en cuanto a su provisión. Años después, a partir de 1885, se establecieron las conexiones de agua para edificios públicos como el hospital San Antonio y se colocaron más surtidores en la ciudad nueva y vieja. Como gran parte de población debía beber agua potable de esos surtidores públicos y ellos no cubrían todo el territorio, también se proveían de las acequias para el consumo cotidiano, cuando estas zanjas eran utilizadas además como desagüe. Esto explica por qué las acequias se consideraran como principales focos de infección y de generación de enfermedades y, por lo tanto, la urgencia de resolver de forma inmediata los sistemas de distribución no solo de agua potable, sino también de cloacas y desagües colectores pluviales ${ }^{(2,3,4)}$.

El organismo encargado de regular e implementar medidas sanitarias era el Consejo Provincial de Higiene creado en 1891. Posteriormente, en 1897, se creó la Dirección Provincial de Salubridad, dirigida por el doctor Emilio Coni, destacado facultativo contratado por el gobierno provincial para encontrar una solución a la problemática sanitaria que atravesaba la provincia. Si bien esta Dirección fue anulada por unos años y se reinstaló el Consejo Provincial de Higiene; en 1907, el gobernador Emilio Civit puso nuevamente en vigencia la Ley Provincial 34 y reinstaló en forma permanente la Dirección General de Salubridad, siendo a comienzos del siglo XX la institución encargada de la sanidad provincial.

\section{Discursos de la elite durante los periodos de epidemias y las medidas profilácticas}

A fines del siglo XIX, tanto desde la esfera gubernamental nacional como provincial, se implementaron distintas políticas preventivo-sanitarias centradas en el mejoramiento de la higiene social y la salud pública que, más allá del tinte político, consideraban que era necesario una reorganización social que permitiría combatir las constantes epidemias que diezmaban a la población y los males que afligían a la ciudad moderna ${ }^{(22,23)}$. Por medio de la higiene social, en un principio, y de la salud pública, en las décadas de 1920 y 1940, se buscó dar a la elite un entorno urbano seguro y controlable y alejar a ciertos sectores del peligro del contagio e incluirlos al mundo social moderno como trabajadores respetables y eficientes ${ }^{(1)}$.

En este sentido, en los discursos enunciados por la prensa y en los informes médicos se señalaba que las medidas debían esforzarse en regular las conductas y hábitos privados y públicos de los sectores más vulnerables, interviniendo en sus modos de vida, tradiciones y actividades sociales (higiene personal, aseo de sus viviendas, dietas alimenticias, celebración de festividades) para mejorar la calidad sanitaria en general. Las autoridades provinciales y municipales eran quienes debían ejecutar su cumplimiento a través de la vigilancia y el castigo mientras que, en la esfera privada, era el patrón quien las debía efectuar por medio de los mismos mecanismos ${ }^{(25)}$. "Tanto las autoridades como las personas acomodadas debían regular las prácticas de los pobres"(26). El objetivo era dirigir y organizar la vida de estos sujetos buscando el orden, la obediencia y el acatamiento de ciertas normas ${ }^{(27)}$.

La elite gobernante construyó sus discursos normativos a partir de nociones provenientes tanto del campo científico como 
del religioso. Así, se sostuvieron una serie de medidas preventivas y de cuidados que debía tener la población para poder combatir las epidemias, marcando como principal causante de esta enfermedad sus propias costumbres. No obstante, no se cuestionaban los hábitos de toda la población, sino los de las clases pobres, cuyos espacios de habitación y sociabilidad eran considerados focos de infección y propagación ${ }^{(26)}$. Por ejemplo, el cólera era conceptualizado como una enfermedad de tipo popular(28), en una ecuación en la que tanto los médicos sociales como los higienistas la asociaron con la pobreza $^{(29)}$. En este registro, las autoridades se propusieron hacer cumplir todas las medidas profilácticas que se pautaran, estipulando que en caso de incumplimiento los infractores serían multados ${ }^{(30)}$, justificando "hasta el empleo de la fuerza, si la ignorancia o el interés [...] pretendiesen oponerse a sus benéficas determinaciones" ${ }^{\prime \prime 28)}$. De ese modo, se adoptaron medidas que segregaban a los sectores populares, a los cuales se les atribuía la culpa del desarrollo de las enfermedades infectocontagiosas ${ }^{(31)}$.

La elite vinculó la noción de "peligro" con todo sujeto, objeto o acontecimiento asociado a estos sectores y a sus ámbitos urbanos. Estas consideraciones eran deudoras del concepto de que la enfermedad era causada por algún factor exógeno al cuerpo humano (teoría miasmática que planteaba que las emanaciones y/o efluidos de materiales orgánicos en descomposición eran las propagadoras de las enfermedades infectocontagiosas, ya que estos transportaban partículas que al ingresar al cuerpo humano provocaban la dolencia. Por ello, se creía que las emanaciones o miasmas infectaban el aire e incubaban epidemias) ${ }^{(32)}$. Por ejemplo, durante la intendencia de Lagomaggiore se expulsó hacia los arrabales todo aquello que era considerado peligroso "como si las bacterias y la contaminación supieran de límites" ${ }^{\prime 2,3,4)}$. Se indicaron aquellos lugares que eran propensos para el desarrollo de las enfermedades infectocontagiosas, como las grandes ciudades, donde se producía el hacinamiento de la población bajo el supuesto de que "mientras más gente hay menos higiene", así como también los hospicios de dementes "por la situación moral de aquellos infelices y hasta por la depravación de sus inclinaciones y apetitos" ${ }^{\prime \prime 3)}$.

También los conventillos se consideraron focos de peligro por el hacinamiento, ya que las epidemias se incubaban en los "albergues de aquella gente, y de estos focos de infecciones part[ían] los gérmenes perniciosos, invadiendo las viviendas del rico y las de personas media acomodadas"(34). No obstante, por ser de menores dimensiones, "esta[ban] más sujetos a la observación de las comisiones sanitarias y [podían] ser desalojados cuando se encuentren en condiciones peligrosas", es decir, se creía que las enfermedades infectocontagiosas buscaban poblaciones densas y en malas condiciones de higiene $^{(35)}$.

Estas opiniones parecían encontrar su fundamento en los diagnósticos realizados, pues un balance efectuado en 1892 acerca de la epidemia de difteria manifestó que los mayores índices de mortalidad se habían producido en aquellas viviendas en donde los sujetos habían descuidado la limpieza, y se encontraban ubicadas en los barrios "bajos, vecinos al canal Zanjon, [y] las casas de inquilinato [,] donde el hacinamiento y la miseria se un[ían] al desaseo de las aguas servidas de las acequias" ${ }^{\prime \prime 36)}$.

El Consejo de Higiene tomó una serie de medidas profilácticas, entre ellas, estableció que las comisiones tendrían autorización para ingresar en las viviendas de la clase proletaria para vigilar el aseo de los patios, letrinas y depósitos de basura, siendo este el "único medio de poder [para] morigerar las costumbres desaseadas del bajo pueblo"(35). Según la elite gobernante y científica, era allí donde nacían los focos de infección que se propagaban "á todas las clases sociales, arrastrando el gérmen aniquilador que anemia la vitalidad a las nuevas generaciones"(35). Para ello, se estipuló que se identificarían las casas por medio de un cartel que dijera difteria o viruela (Figura 1), y el cual permanecería durante 30 días con el objetivo de identificar y marcar el "peligro"(37). De este modo, los higienistas cuestionaban el principio de la 


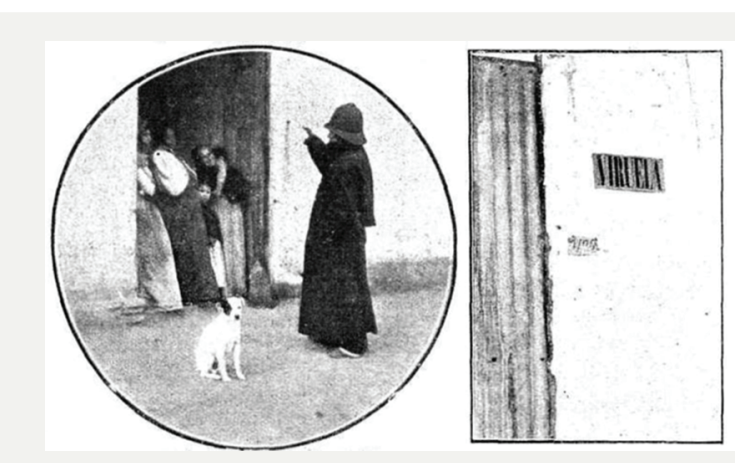

Figura 1. Vigilante que prohibía a las personas salir de sus viviendas y cartel que identificaba la vivienda de un varioloso. Mendoza, Argentina, 1911.

Fuente: La viruela. Caras y Caretas, 22 de julio de 1911 ${ }^{(38)}$.

propiedad privada, utilizando como excusa el argumento de la sanidad pública y, de tal forma, la vigilancia sobre el sujeto se convertía "en una consecuencia natural de la política de prevención"(28).

Por otro lado, las autoridades implementaron medidas de aislamiento. Así, los sujetos que habitaban los conventillos fueron desalojados y distribuidos en zonas aledañas al zanjón (Figura 2), a la intemperie y en pésimas condiciones higiénicas, agravando con ello su propia situación, ya que el agua de este canal constituía un foco de infección porque en él desembocan los restos del matadero ${ }^{(38)}$.

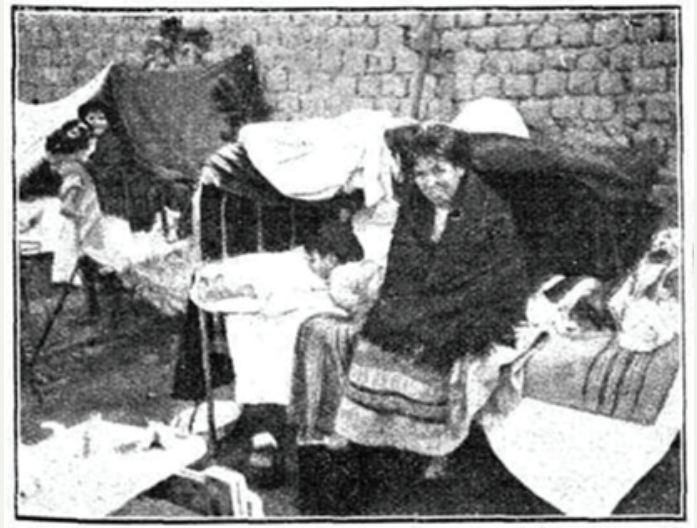

Figura 2. Traslado de habitantes al campamento, ubicado en las orillas del zanjón, durante el azote de la epidemia de viruela. Mendoza, Argentina, 1911.

Fuente: La viruela. Caras y Caretas, 22 de julio de 1911 ${ }^{138)}$.
Se generaba un círculo vicioso por el cual se desplazaba a estos grupos considerados potencialmente favorables al desarrollo de las enfermedades, debido a sus costumbres supuestamente poco higiénicas pero, a la vez, se estigmatizaban esos espacios, intentando controlarlos a partir de diversos dispositivos.

Además, se insistía en las falencias respecto de los hábitos de aseo personal, apuntando a la limpieza individual con el objetivo de disciplinar el cuerpo, ocultando sus "olores y sus sudoraciones cuando no su anulación"(39), así como también, en los modos alimenticios, ya que si bien era sabido que las primeras frutas y legumbres sin madurar eran propicias a provocar el cólera, se sostenía que las personas del pueblo no tomaban ningún tipo de recaudo para evitarlo, a lo que se sumaba el consumo de vinos y otras bebidas adulteradas ${ }^{(40)}$. Además, se agregaba que usaban la misma agua con diversos fines: bebida, baño, lavandería y letrina, como ocurría, "en la acequia del Jarrillal, que prove[ía] de agua [a] Panquegua y la Chimba, [con] los peones que trabajan en la sierra"(26).

Asimismo, se aconsejaba necesario evitar los excesos físicos y mentales como la tristeza, el enojo y el miedo ${ }^{(41)}$. Estas recomendaciones buscaban influir sobre la moral de los sujetos, haciéndoles comprender la utilidad de las medidas tomadas por el gobierno y la mejora que ellas generaban en la calidad de vida, ello en un contexto de representaciones en el que, siguiendo los planteos de la medicina de antaño, se sostenía que el abatimiento moral y el miedo predisponía al sujeto a sufrir el contagio ${ }^{(42)}$.

No obstante, estos padecimientos no solo fueron asociados a los sectores populares en general, sino también específicamente a la figura del inmigrante. Se consideraba que eran "hombres de climas diferentes, de costumbres y hábitos distintos a los nuestros y [no contaban con] los medios necesarios para hacer cómoda la vida y usar las verdaderas prácticas hijiénicas", por lo que las autoridades municipales debían "observar y aislar convenientemente á todos los inmigrantes y viajeros que arriben [...] con procedencia de los centros infestados" ${ }^{\prime(43)}$. 
Las representaciones de la elite manifestadas a través de la prensa vinculaban el "peligro" con la gente pobre, a pesar de que en las décadas de 1870 y 1880 todos los sectores de la sociedad habían sufrido las mismas enfermedades infectocontagiosas ${ }^{(22,23)}$. No obstante, durante el desarrollo de la difteria en 1895, esta segmentación social de las culpas sanitarias comenzó a ser muy tenuemente denunciada, develándose cómo el peso del control y el disciplinamiento se enfocaba solo a un grupo social. Así, se dio a conocer el caso del contagio de una familia acomodada, afirmándose que para poder "equilibrar el cargo que se hace al pobre"(44), era necesario también vigilar qué se hacía en los otros sectores sociales. En este sentido, en la casa de una señora respetable por su nombre y sus vinculaciones, también por su fortuna, se produjo la difteria. Ante ello el médico, quien también era un conocido facultativo, aconsejó la quema de los enseres del diftérico, efectuándose en una casa desocupada aledaña, pero sin haber tenido en cuenta los cuidados necesarios. De tal forma:

...la posición social proteje esos abusos, los escusa el nombre, el secreto mas sigiloso, sino el respeto mas profundo, los guarda de miradas y comentarios. En medio de esta indiferencia culpable, [...], podemos presenciar, á la plebeya que pasea una hija enferma de escarlatina por el comercio, y á la patricia que guarda y conserva la difteria en el corazon de dos centrales manzanas de la ciudad. La Asistencia pública [...] habria Ilevado á la primera a la cárcel [...], arrebatándole su hija para echarla al abandono salufiero del lazareto, habria hecho gravitar sobre la madre infeliz todo el peso de la salud pública; pero se habria inclinado con respetuosa cortesía delante de la otra. ${ }^{(37)}$

Si bien el matutino Los Andes adhería a la representación social de la elite dirigente, también reclamaba la vulnerabilidad de los sectores populares frente a los planes reguladores. Como denuncia el artículo periodís- tico, la aplicación de las medidas sanitarias sobre los sujetos dependía de las condiciones socioeconómicas del grupo que integraban. Por lo general, si pertenecían a los sectores populares eran censados y enviados a la Asistencia Pública mientras que, si eran de la elite, se los aislaba en sus viviendas privadas y recibían la atención de un médico particular, sin mediar notificación -en la mayoría de los casos- a los miembros encargados de dicha institución ${ }^{(45)}$. La exclusión constituía un mecanismo del cual se consideraba que depuraba el ámbito urbano y se institucionalizaba a través del lazareto (Figura 3), un dispositivo que, junto con la vigilancia, buscaban distribuir a los sujetos en el espacio y controlar su salud ${ }^{(22,23)}$.

Por otra parte, durante el desarrollo de la viruela en 1889 , se había evidenciado que el tratamiento eficaz era la vacunación; no obstante, continuó a lo largo de varios años provocando estragos entre la población precisamente por no generalizarse la inoculación correspondiente. En este sentido, se les recomendaba a los padres de familia vacunar de forma inmediata a sus hijos "si no quieren experimentar el dolor de perderlos". Posteriormente, en 1896, esta medida se hizo obligatoria a toda la población de la provincia ${ }^{(46)}$. Esta práctica se convirtió en parte de una estrategia a partir de la cual los higienistas justificaron una mayor intervención sobre el

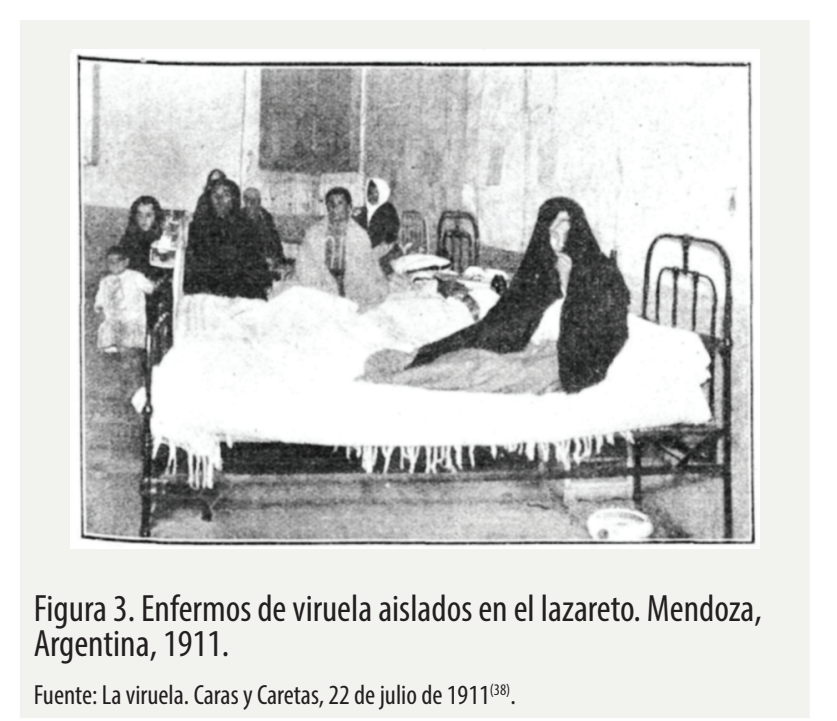


cuerpo para lograr sus objetivos de vigilancia y disciplinamiento a los fines de lograr la seguridad del cuerpo social(47).

En síntesis, los reglamentos sancionados a fines del siglo XIX buscaban delimitar los sectores de la ciudad en los que debían habitar los enfermos y establecer una serie de normas que indicaran cuándo se podía salir, cómo, a qué hora, qué debían hacer en sus casas, qué tipo de alimentación debían comer. Esto, además de vetarles tal o cual clase de contacto, los obligaba también a presentarse frente a inspectores o dejarlos ingresar en sus viviendas. En definitiva, buscaban disciplinar las formas de vida de un sector definido de la población ${ }^{(48)}$.

A principios del siglo XX, durante la epidemia de gripe, si bien el discurso de la elite, que se manifestaba a través de la prensa, continuó apuntando a las costumbres y prácticas de los sectores populares, lo hacía revelando la situación social en que se encontraban. Ello era consecuencia de un sistema económico desigualitario, por lo que ya no eran señalados como un "mal social", es decir, como generadores y vehículos de contagio de las enfermedades. Esta situación se debió, también, a los avances en el campo de la bacteriología, que permitió vincular la existencia de enfermedades con agentes infecciosos específicos y no como consecuencia de determinadas costumbres o valores morales. Asimismo, reflejaba el cambio en el clima de opinión que representaron los gobiernos radicales lencinistas. Pero, además, se empezó a precisar que este tipo de padecimientos también se desarrollaban en los sectores acomodados:

...comienza en los cuárteles y se propaga a la cárcel, a los conventillos y por último a toda la ciudad. [...] [Pero] también en respetables hogares de esta sociedad. Ha sido necesario que el terrible flagelo azote en forma inexorable dos o tres hogares conocidos, tronchando vidas jóvenes y estimables, para que recién cunda la alarma y las autoridades sanitarias tomen las medidas [necesarias] ${ }^{(49)}$.
De este modo, las nuevas ideas de higiene, originadas en la revolución bacteriológica, fueron incorporándose paulatinamente en las prácticas sociales, terminando por convertirse muchos de sus principios en necesidades materiales y morales de la vida en la ciudad moderna ${ }^{(22,23)}$. Además, también pasaron a considerarse como espacios de contagio los lugares cultos y aun "adelantados", como las escuelas, teatros, cines y edificios públicos, pues en ellos se propagaba el flagelo por la "aglomera[ción de] multitudes y microbios" ${ }^{\prime \prime 50}$. Se sostenía la noción de que la gripe era una enfermedad que no distinguía ni edad, ni sexo, ni condición social, siendo numerosas las víctimas conocidas como "N.N." (51).

También sucedió con la tuberculosis: el periódico La Palabra expresaba que se había producido un descenso de la mortalidad en aquellos países en los que "la política industrial se ha[bía] seguido a la par que la de la higienización de las fábricas y talleres, así como en favor de las Ilamadas clases proletaria y media" ${ }^{\prime(52)}$. Además, consideraba que esta dolencia era de tipo socioeconómica, ya que el mayor porcentaje de moribundos se producía en aquellos lugares donde la ocupación, las condiciones de trabajo y remuneración, junto con necesidades básicas no satisfechas, hacía estragos en la población "que habita[ba] en infectos cuchitriles, en piezas húmedas [con] falta de la alimentación necesaria, y con una prole generalmente que sobrepasa en mucho al presupuesto de recursos de que disponen"(53). No obstante, exponía que si mejoraban las condiciones de trabajo y los salarios, así como la higienización de las viviendas obreras, se optimizaría la calidad de vida de estos sectores y disminuiría el flagelo de esta enfermedad. Además, reclamaba a los médicos que divulgaran el verdadero origen del mal y denunciaran a las autoridades "los casos en que se contradicen las disposiciones vigentes sobre la higiene y el trabajo en las fábricas y los talleres"(53).

Durante las epidemias de tuberculosis y de gripe el discurso gubernamental de Lencinas continuaba vinculando las enfermedades con los sectores populares, pero los desplazaba de su rol de culpables, asignado según 
ellos por los gobiernos oligárquicos anteriores. De este modo, en los argumentos de la elite hubo un cambio en torno a las epidemias que colocó a dicho grupo en rol de víctimas, siendo considerado su modo de vida consecuencia de un sistema económico y social deficiente. En este registro, denunciaba la desigualdad de posibilidades de estos grupos a la hora de enfrentar las enfermedades y la muerte, y la falta de compromiso de los sectores más acomodados para colaborar en la causa. Esto llevó a que también se modificaran ciertas prácticas y medidas sanitarias implementadas hasta entonces, como el mecanismo de exclusión y marginación. Decían buscar la integración por medio de la mejora de las necesidades básicas, pero también de otras, como las condiciones dignas de trabajo. Además, recalcaban la importancia de establecer pensiones para los enfermos que no pudieran trabajar, ya que de otro modo se veía perjudicada toda la familia. Es importante mencionar que, durante este periodo, se estableció el derecho a un seguro y pensión a partir de la creación de la Caja Obrera de Pensión a la Vejez e Invalidez ${ }^{(54)}$.

Asimismo, los dirigentes hacían alusión a la importancia de extender las prácticas higiénicas a toda la población. En el debate legislativo producido sobre el estado sanitario provincial en 1919, los legisladores proponían que desde el Estado se divulgaran los conocimientos necesarios. De hecho, entre otras medidas, la minuta de interpelación que proponían al Poder Ejecutivo establecía: "Intensificación de la educación higiénica en el pueblo"(53). En este sentido, la instrucción formal era considerada como un vehículo para enseñar las prácticas higiénicas. Se proponía además transmitir las normas a la población en general. Así, mediante conferencias públicas, se podría enseñar a los analfabetos y demás personas que estaban excluidas del sistema educativo formal, de hecho, en la época era muy elevado el porcentaje de población no instruida (en 1914 había un $42 \%$ de analfabetos en Mendoza). Por otro lado, en el mismo debate se hacía referencia a la importancia de proporcionar viviendas para que los trabajadores habitaran en condiciones higiénicas. Aludían así al proyecto de ley lencinista presentado en 1919 que postulaba la construcción de 250 casas para obreros en Capital y departamentos aledaños $^{(55)}$.

\section{Ampliación y profesionalización de la atención sanitaria}

Algunos trabajos recientes, especialmente la compilación de Rodríguez Vázquez y Ra$\mathrm{ffa}^{(56)}$, analizan la profesionalización del Estado Provincial en Mendoza considerando las respuestas institucionales y las estrategias gubernamentales en relación con la conformación de nuevas agencias estatales y el ingreso de personal técnico a la burocracia. Las autoras hacen referencia no solo a las tradicionales profesionales liberales sino también a las carreras que tuvieron gran peso en la provincia (tales como la de Arquitectura y la de Enología). No obstante, si bien hay algunos textos que analizan las políticas públicas y la profesionalización del campo de la salud ${ }^{(57,58,59)}$ en Mendoza, son escasos los escritos referentes a los primeros años del siglo XX.

En relación con la asistencia médica estatal, se sabe que con anterioridad a las gobernaciones lencinistas existían algunos hospitales (Provincial, San Antonio, Municipal de General Alvear, se había comenzado a construir el de Maipú y el de San Martín) y salas de primeros auxilios. Lencinas, en consonancia con su discurso antioligárquico, se propuso extender y mejorar los servicios de asistencia médica a los sectores populares, efectivizando la descentralización geográfica iniciada con los gobiernos conservadores ${ }^{(11)}$. Así, llevó a cabo refacciones en el hospital San Antonio, concluyó obras complementarias en el hospital de Maipú y finalizó las del hospital Regional de San Martín, propuso construir un hospital moderno en la ciudad capital destinado a enfermedades infectocontagiosas y a la atención de tuberculosos, sugirió crear servicios para la atención de enfermedades venéreas, ampliar la atención de niños y fundar un Instituto de Puericultura para educar a las madres. 
Posteriormente, en 1922, Carlos W. Lencinas hizo una considerable ampliación del presupuesto destinado a salud pública. Al igual que su padre, extendió servicios asistenciales a los departamentos y amplió el número de camas para internación. En 19231924 se crearon diversos servicios en los hospitales Provincial y San Antonio, también el instituto "Pasteur", de bacteriología y laboratorio de anatomía patológica (Figura 4), salas de primeros auxilios en los departamentos, ampliación de la Asistencia Pública con servicios de pediatría, clínica médica, ginecología y obstetricia. Además, en 1924, se creó la Cantina Maternal y Dispensario de Lactantes, por la cual el Estado intervino dando apoyo alimentario a las madres que lo necesitaran, controlando la evolución de los lactantes y transmitiendo la enseñanza de pautas de higiene personal, y normas sobre manipulación y preparación de alimentos. Asimismo, en ese mismo año se terminó el Hospital de San Rafael y el Hospital José Néstor Lencinas, especializado en enfermedades infectocontagiosas. El antiguo Lazareto fue transformado en hospital de crónicos, con el nombre de Luis C. Lagomaggiore. En 1907 Mendoza contaba con 700 camas, y veinte años después había $1.250^{(21)}$.
Las cifras de enfermos de tuberculosis eran alarmantes y las autoridades consideraban que se debía a que principalmente no se contaba con un lugar especial para aislar al enfermo ${ }^{(61)}$. En el Hospital José Néstor Lencinas se destinaron dos pabellones a los afectados del pulmón de ambos sexos y uno a niños atacados de tuberculosis ósea, además de poseer un solarium para su tratamiento. Asimismo, se contó con otro pabeIlón destinado al resto de las enfermedades infectocontagiosas, en donde los dolientes se encontraban totalmente divididos y aislados. De este modo, el cuerpo del individuo fue introduciéndose en un sistema de medicalización cada vez más denso y amplio, en el que los enfermos comenzaron a ser diagnosticados y clasificados según los parámetros establecidos y a ser diferenciados, jerarquizados y distribuidos en diferentes espacios o pabeIlones de acuerdo al tipo de tratamiento que se les aplicara, proceso en el que intervino de forma recurrente e influyente la figura del médico y las enfermeras.

Resulta importante observar cómo a partir de los avances médico-científico en vacunación y las consecuentes políticas de inoculación implementadas se fue disminuyendo el porcentaje de muertes. Por ejemplo,

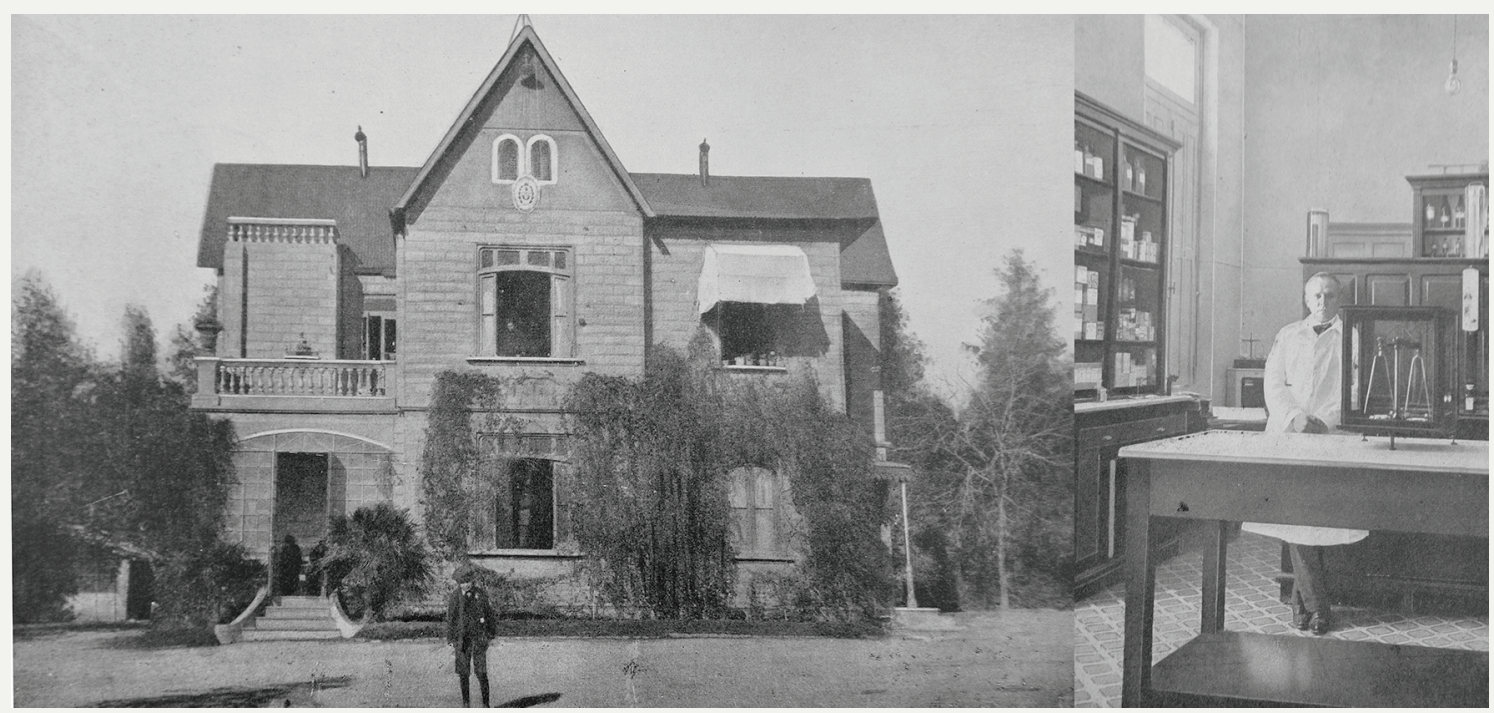

Figura 4. Laboratorio Pasteur, inaugurado en 1924. Mendoza, Argentina.

Fuente: Memoria presentada a la Honorable Legislatura por el ministro de Industrias y Obras Públicas, Ingeniero Leopoldo Suárez ${ }^{(60)}$. 
en 1889 , el $43,5 \%$ de las defunciones fueron por enfermedades infectocontagiosas, entre las cuales la viruela era la principal. Luego de las campañas antivariólicas, este número disminuyó de manera significativa y se logró erradicar los brotes. De hecho, a principios del siglo XX, el porcentaje de defunciones por enfermedades infectocontagiosas fue menor al $20 \%$ del total de muertes, exceptuando el año 1919, que ese porcentaje ascendió debido a la epidemia de gripe.

Según Richard Jorba ${ }^{(11)}$, a la menor cantidad de decesos producidas durante las gestiones lencinistas debe agregarse el lugar en que ocurrieron. Los fallecimientos en conventillos disminuyeron un $89 \% \mathrm{y}$, los ocurridos en hospitales, aumentaron un 4,25\%. Estas cifras confirman una preocupación por atender a los grupos más carenciados, radicados en conventillos, que fueron trasladados e internados en hospitales. Según el autor, mejoró la cobertura médico-asistencial pese a una notoria difusión geográfica de los conventillos $^{(11)}$. En 1923 murieron en total 7.647 personas en Mendoza, de las cuales 15 fallecieron en conventillos, 32 en la vía pública, 1.392 en hospitales y centros asistenciales y 6.183 en casas particulares. $\mathrm{Al}$ año siguiente el número de muertos en conventillos se redujo a $9^{(15)}$.

Este fenómeno es una parte fundamental del proceso de ampliación y profesionalización que fue adquiriendo la atención sanitaria estatal. Ya no se moría en una casa, atendido tal vez por un médico, sino en un hospital con un equipamiento adecuado y con profesionales diversos a cargo (enfermeros, médicos especialistas, cirujanos). No obstante, el incremento del índice de personas fallecidas que habían sido hospitalizadas fue creciendo de manera muy paulatina. Del mismo modo, creció el número de nacidos en hospitales y fue disminuyendo el porcentaje de partos en las viviendas.

Ahora bien, más allá del lugar del faIlecimiento, es interesante considerar si las muertes se produjeron con o sin asistencia médica, ya que da cuenta de la cobertura médico sanitaria de los diferentes sitios. Tal es el caso de la sección oeste, en la cual en 1923 murieron 1.245 personas habiendo sido asistidas, y solo dos que no recibieron asistencia médica, lo cual representa un $0,2 \%$ del total de muertes. Por el contrario, en la sección este de la ciudad de Mendoza hubo 1.022 personas fallecidas que habían recibido atención y 170 que no fueron atendidas, representando un $14,3 \%$ del total. Es posible visibilizar la diferencia entre las dos ciudades (antigua y nueva) también a partir de la forma de muerte. En una, el Estado garantizaba de manera fehaciente la asistencia sanitaria de los moribundos, y en la otra había una parte importante de la población que quedaba abandonada a su suerte. Situación que se ve reflejada también a nivel departamental.

Del mismo modo, la implementación de medidas preventivas y paliativas (vacunación, desinfección e inspección) por la Dirección de Salubridad trajo aparejada una disminución significativa de la tasa de mortalidad provincial. Estas medidas produjeron una disminución del porcentaje de enfermos y recayó en una mengua significativa de la tasa de mortalidad provincial. El índice de mortalidad del año 1919 era del 23,7 por mil habitantes. Esta cifra fue descendiendo en los años posteriores llegando a 17,23 por mil en 1928 $8^{(11,20)}$.

Por otro lado, es importante mencionar que durante el periodo lencinista se propuso ampliar el servicio de agua potable, se proyectó la red de cloacas en la capital mendocina, y se extendió el servicio de agua corriente hacia los departamentos, medidas que mejoraron de manera significativa la calidad del ambiente urbano provincial.

Además, junto al incremento de la intervención estatal en la salud pública, creció el número de profesionales de la salud. En 1927 había 309 profesionales con título nacional (162 médicos con título nacional, 82 farmacéuticos, 26 dentistas, 7 veterinarios, 34 parteras) y 20 con título extranjero (8 médicos y 12 parteras $)^{(15)}$. Asimismo, se reglamentó de manera más exhaustiva la actividad médica. Desde fines del siglo XIX el Estado comenzó a implementar una serie de políticas sanitarias relacionadas con el ejercicio profesional de la medicina, otorgando a la figura del médico un lugar destacado y reafirmando su poder 
como experto, a diferencia del curandero, colocado en un rol de ignorante y vinculado al saber popular ${ }^{(62)}$.

En la provincia, la Dirección General de Salubridad persiguió al curanderismo para favorecer a los médicos y a las clases pobres, ya que se decía que estas abandonaban a sus moribundos en manos de los curanderos. Se buscó alejar a dichos grupos de las "explotaciones y errores" de los charlatanes y difundir "las prescripciones científicas que curan y evitan las enfermedades é impiden su propagación"(63).

Años después, en 1927, el Estado avanzó aún más y sancionó la nueva Ley Sanitaria 926. En la nueva normativa se le concedían más atribuciones a la Dirección General de Salubridad y al Consejo Consultivo de Higiene y se regulaba el ejercicio de la medicina, la obstetricia y la actividad farmacéutica. Los principales aspectos del plan de organización fueron:

...1 $1^{\circ}-$ El levantamiento de un catastro sanitario domiciliario que permitiera "conocer la ciudad por dentro" y colocarse en condiciones de poder atender a todos esos núcleos de población que son los primeros en sufrir las influencias epidémicas y cuyas costumbres y falta de higiene facilitan la propagación de todos los males [...]; 20- El ejercicio ilegal de la medicina. Se decretará la guerra al curanderismo, pero se exigirá de los facultativos diplomados; $3^{\circ}$-El ejercicio de la farmacopea se consentirá solamente a los farmacéuticos nacionales y se castigará con penas severísimas a los que burlen esta disposición. ${ }^{(64)}$

Esta legislación se sancionó en un contexto de formación y regulación de las actividades profesionales (en 1922 se había presentado un proyecto de ley para reglamentar las carreras de Ingeniería, Agrimensura y Arquitectura), y enmarcada en un proceso de ampliación de la función estatal en materia social. Por un lado, la ley estipulaba el establecimiento de un mayor control para detectar los casos de enfermos a fin de mermar el contagio (desinfecciones e inspecciones). Por otro lado, aludía específicamente a las actividades curativas; solo podrían ejercer la profesión los médicos que hubieran obtenido su título de una universidad nacional o los extranjeros que lo hubiesen revalidado, instaurando de ese modo una regulación mucho más exhaustiva del ejercicio de la medicina, obstetricia y farmacia (en la legislación anterior se preveía que, en algunos casos, la Dirección de Salubridad podría elegir "idóneos" sin título habilitante). Además, se pautaba que "las vacantes que se produzcan en los puestos técnicos de hospitales y Asistencia Pública serán Ilenados por concurso"(64) así, se transparentaba la elección de cargos de salud, priorizando la selección de los más capacitados.

Además, el higienismo adquirió legitimidad como herramienta de intervención gubernamental y pasó a formar parte del imaginario social y urbano de las elites, lo que potenció el papel de las instituciones médicas ${ }^{(65)}$. Por otra parte, a partir de la bacteriología y microbiología se introdujeron saberes que marcaron un punto de partida del poder médico sobre el resto de la sociedad. Según Di Liscia ${ }^{(62)}$, el control médico fue un proceso que implicó esfuerzos tendientes a homogeneizar las prácticas curativas y no una cuestión automática en la que autoridades acordaban totalmente entre sí y con los facultativos e instituciones sanitarias. Estos profesionales se vincularon con las diferentes instituciones estatales y establecieron de forma fehaciente una capacidad superior para resolver problemas de salud urgentes, tal como fueron las epidemias.

Si bien existen investigaciones que analizan la profesionalización del sistema de salud y la aplicación de políticas públicas en otras provincias ${ }^{(47,66,67,68,69,70,71,72,73,74,75,76)}$, en este trabajo el interés se centró en el caso mendocino, y en explicar cómo en Mendoza se modificó el discurso esgrimido por la elite no solo a partir de los avances médico-científicos que conllevaron a la profesionalización del campo de la salud y al fortalecimiento de la autoridad del médico, sino que este estuvo relacionado además con las modificaciones a nivel político. En este sentido, el discurso antioligárquico esgrimido por los seguidores del 
gobernador Lencinas a nivel político, tuvo su correlato a la hora de gestar políticas públicosanitarias, generando que no solo a nivel discursivo, sino en la proyección, las políticas públicas estuvieran destinadas a toda la población. De hecho, durante el periodo lencinista se propusieron proyectos, tales como la expropiación de Villavicencio en 1918 -edificación de viviendas populares-, y la democratización del parque General San Martín a partir de la creación de un paseo peatonal y las concesiones a los clubes de fútbol ${ }^{(77)}$.

\section{CONSIDERACIONES FINALES}

Entre fines del siglo XIX y comienzos del XX los discursos de la elite mendocina durante los brotes epidémicos fueron desplazándose de argumentos que articulaban elementos diversos, entre ellos religiosos y morales, a otros en los que pasaron a tener preeminencia primero y luego presencia absoluta, los preceptos científicos e higiénicos. En un primer momento, las medidas implementadas por los dirigentes para mejorar el estado sanitario de la provincia durante las epidemias estaban destinadas a regular las prácticas de los sectores populares, ya que las representaciones le habían adjudicado a estos y sus espacios la noción de peligro. De este modo, las críticas hacia estos sujetos estuvieron focalizadas en una serie de puntos recurrentes: la suciedad y el desaseo de sus viviendas y habitaciones, los malos hábitos alimentarios y sus vicios o excesos, sus vestimentas y su atmósfera contaminada. Así, el Estado provincial reglamentaba las prácticas en el ámbito público, que abarcaba incluso la intimidad de los sectores populares, mientras que los "patrones" lo hacían en el ámbito privado (aun cuando en

\section{REFERENCIAS BIBLIOGRÁFICAS}

1. Losada L. Historia de las elites en la Argentina: Desde la conquista hasta el surgimiento del peronismo. Buenos Aires: Sudamericana; 2009.

2. Persello AV. Historia del radicalismo. Buenos Aires: Edhasa; 2007. ciertas ocasiones escapaban a las regulaciones estatales), ya que consideraban que solo los pobres eran los causantes y propagadores de las epidemias.

No obstante, durante el desarrollo de la difteria, la prensa denunció que también los sectores acomodados padecían estas mismas enfermedades. Esto se acentuó durante el azote de la gripe y la tuberculosis (gobiernos lencinistas), que produjo un cambio en la concepción de los dirigentes. Si bien se continuó considerando a los sectores populares como fuente principal de propagación de las enfermedades infectocontagiosas (debido, principalmente, a conductas antihigiénicas y a sus condiciones de vivienda), estos eran vistos como víctimas de las falencias del sistema socioeconómico y por ello el Estado debía socorrerlos. Además, ya no se atribuía exclusivamente la responsabilidad del contagio a los pobres, sino que se visibilizaba claramente que las dolencias afectaban a todos los grupos sociales sin distinción de edad, sexo, ni condición social.

Las modificaciones en el discurso se debieron a los avances científicos sanitarios y a la profesionalización de las actividades curativas. A partir de la reforma de la Ley Sanitaria, el Estado comenzó a legitimar solo a ciertos actores; pero, por otro lado, la medicina como ciencia también se benefició del lugar prioritario que le otorgó el Estado y fortaleció su legitimidad a través de las instituciones. Esto estuvo relacionado, además, con los cambios producidos a nivel político. El discurso antioligárquico esgrimido por los lencinistas, tuvo su correlato a la hora de pensar y aplicar políticas público-sanitarias. Por último, es importante destacar que tanto las medidas preventivas y paliativas como la ejecución de obras públicas generaron una mejora significativa del estado sanitario general de Mendoza en las primeras décadas del siglo XX.

3. Ansaldi W. La trunca transición del régimen oligárquico al régimen democrático. En: Falcón R, (dir.). Nueva Historia Argentina. Tomo VI. Buenos Aires: Sudamericana; 2000. p. 15-57.

4. Rock D. El radicalismo argentino, 1890-1930. Buenos Aires: Amorrortu; 1975. 
5. Ansaldi W, Giordano V. América Latina: La construcción del orden. Buenos Aires: Ariel; 2012.

6. Sábato $H$, Ternavasio $M$, De Privitiello L, Persello V. Historia de las elecciones en la Argentina. Buenos Aires: El Ateneo; 2011.

7. Alonso P. La Unión Cívica Radical: fundación, oposición y triunfo (1890-1916). En: Lobato M, (dir.). Nueva Historia Argentina. Tomo V. Buenos Aires: Sudamericana; 2000. p. 209-259.

8. Mellado V. “La Liga Patriótica Argentina: Una aproximación a las redes asociativas de los elencos políticos y culturales de Mendoza (1919-1930). Entrepasados: Revista de Historia. 2007;16:1-19.

9. Rodríguez C. Lencinas y Cantoni: El populismo cuyano en tiempos de Yrigoyen. Buenos Aires: Editorial Belgrano; 1979.

10. Lacoste P. La Unión Cívica Radical en Mendoza y en la Argentina, 1890-1946. Mendoza: Ediciones Culturales; 1995.

11. Richard Jorba R. Los gobiernos radicales de los Lencinas en Mendoza, salud pública y vivienda popular, 1918-1924: Rupturas y continuidades con el orden conservador. Avances del Cesor. 2011;8(8):31-62.

12. Armus D. El descubrimiento de la enfermedad como problema social. En: Lobato $M$, (dir.). El progreso, la modernización y sus límites (18801916). Buenos Aires: Sudamericana; 2000. p. 507-552.

13. Cirvini S. El ambiente urbano en Mendoza a fines del siglo XIX: La higiene social como herramienta del proyecto utópico del orden. En: Rodríguez Lapuente M, Cerutti Guldberg H. (comp.). Arturo Roig: Filósofo e historia de las ideas. Guadalajara: UM; 1989. p. 107-143.

14. Coni E. Saneamiento de la Provincia de Mendoza. Buenos Aires: Imprenta de M. Biedma; 1897.

15. Dirección General de Estadísticas de Mendoza. Anuario correspondiente al año 1914. Buenos Aires: Talleres S. A. Casa Jacobo Peuser, LTDA; 1916.

16. Dirección General de Estadísticas de Mendoza. Anuario correspondiente al año 1923. Buenos Aires: Talleres S. A. Casa Jacobo Peuser, LTDA; 1924.

17. Dirección General de Estadísticas de Mendoza. Anuario correspondiente al año 1924. Buenos Aires: Talleres S. A. Casa Jacobo Peuser, LTDA; 1926.

18. Dirección General de Estadísticas de Mendoza. Anuario correspondiente al año 1925. Buenos Aires:
Talleres S. A. Casa Jacobo Peuser, LTDA; 1926.

19. Dirección General de Estadísticas de Mendoza. Anuario correspondiente al año 1926. Buenos Aires: Talleres S. A. Casa Jacobo Peuser, LTDA; 1928.

20. Dirección General de Estadísticas de Mendoza. Anuario correspondiente a los años 1927-1929. Buenos Aires: Talleres S. A. Casa Jacobo Peuser, LTDA; 1931.

21. Orfila JA. Memoria correspondiente al año 1927 presentada al Ministerio de Obras Públicas por el director general de Salubridad. Mendoza; 1928.

22. Cerdá JM. Mercado de trabajo y condiciones de vida en Mendoza a comienzos del siglo XX. Mundo Agrario. 2006;6(12):1-26.

23. Cerdá JM. Características de la vivienda mendocina en la primera mitad del siglo XX. Población y Sociedad. 2007-2008;14-15(1):33-70.

24. Ponte R. La fragilidad de la memoria. Mendoza: Ediciones Fundaciones CRYCIT; 1999.

25. La policía y la epidemia. Los Andes. 22 dic 1886. Localizado en: Hemeroteca Mayor de la Biblioteca General San Martín, Mendoza, Argentina.

26. Digno de proceder. Los Andes. 23 dic 1886; año IV número 65. Localizado en: Hemeroteca Mayor de la Biblioteca General San Martín, Mendoza, Argentina.

27. Gargiulo MC. El cólera: oportunidades de control y resistencia populares: Tucumán, 18861887. Estudios Sociales. 2011;41(1):97-125.

28. Departamento Nacional de Higiene. Instructivo para prevenir a la República Argentina contra la epidemia de cólera. Buenos Aires: Departamento Nacional de Higiene; 1887.

29. Salvatore R. Sobre el surgimiento del estado médico en la Argentina (1890-1940). Estudios Sociales. 2001;20(1):81-114.

30. Hijiene. El cólera y el miedo. El Ferrocarril. 3 dic 1886. Localizado en: Hemeroteca Mayor de la Biblioteca General San Martín, Mendoza, Argentina.

31. Cueto M. El regreso de las epidemias: salud y sociedad en el Perú del siglo XX. Lima: IEP; 1997.

32. Carbonetti A. Cólera y conflicto en la ciudad de Córdoba, Argentina (1867-1868). Boletín Mexicano de Historia y Filosofía de la Medicina. 2007;10:71-78. 
33. Los casos sospechosos. El Ferrocarril. 10 dic 1886. Localizado en: Hemeroteca Mayor de la Biblioteca General San Martín, Mendoza, Argentina.

34. A quien le venga el sayo. Los Andes. 4 mar 1891; v. VIII, n. 1867. Localizado en: Hemeroteca Mayor de la Biblioteca General San Martín, Mendoza, Argentina.

35. Sobre la difteria. Los Andes. 23 mar 1892; v. IX, n. 2175. Localizado en: Hemeroteca Mayor de la Biblioteca General San Martín, Mendoza, Argentina.

36. Higiene pública. Los Andes. 11 feb 1893; v. X, n. 2431. Localizado en: Hemeroteca Mayor de la Biblioteca General San Martín, Mendoza, Argentina.

37. Gobierno de Mendoza. Rejistro oficial de la provincia de Mendoza. Mendoza: Imprenta de El Porvenir; 1892. Localizado en: Biblioteca de la Municipalidad de Capital, Mendoza, Argentina.

38. Terrible epidemia de difteria. Caras y Caretas. 22 jul 1911; v. XIV n. 668. Localizado en: Hemeroteca digital de la Biblioteca Nacional de España.

39. Barrán JP. Historia de la sensibilidad en el Uruguay. Uruguay: Editorial de la Banda Oriental; 1989.

40. Advertencias. La Palabra. 17 dic 1886. Localizado en: Hemeroteca Mayor de la Biblioteca General San Martín, Mendoza, Argentina.

41. Contra el cólera. El Ferrocarril. 14 nov 1886. Localizado en: Hemeroteca Mayor de la Biblioteca General San Martín, Mendoza, Argentina.

42. Delumeau J. El miedo en Occidente. Madrid: Taurus; 1989.

43. Precauciones. La Palabra. 11 dic 1886. Localizado en: Hemeroteca Mayor de la Biblioteca General San Martín, Mendoza, Argentina.

44. Realidades amargas: Los niños condenados á muerte. Los Andes. 6 jun 1895; v. XII, n. 3101, p. 1. Localizado en: Hemeroteca Mayor de la Biblioteca General San Martín, Mendoza, Argentina.

45. Raffa C. El imaginario sanitario en Mendoza a fines del siglo XIX: obras de higiene y salubridad durante la intendencia de Luis Lagomaggiore (1884-1888). Historia Social y de las Mentalidades. 2007;2(XI):173-200.

46. Municipalidad de la Ciudad de Mendoza. Memoria de la Municipalidad de la Ciudad de Mendoza 1899. Mendoza: Tipografía Antigua Casa Mickes; 1900.
47. Di Liscia MS. Marcados en la piel: vacunación y viruela en Argentina (1870-1910). Ciência \& Saúde Coletiva. 2011;16(2):409-422.

48. Foucault M. Seguridad, territorio y población. Buenos Aires: FCE; 2006.

49. La grippe. La Palabra. 4 jun 1919. Localizado en: Hemeroteca Mayor de la Biblioteca General San Martín, Mendoza, Argentina.

50. La salud pública. La Palabra. 6 jun 1919, p. 1. Localizado en: Hemeroteca Mayor de la Biblioteca General San Martín, Mendoza, Argentina.

51. La grippe. La Palabra. 17 jul 1919, p. 1. Localizado en: Hemeroteca Mayor de la Biblioteca General San Martín, Mendoza, Argentina.

52. La lucha contra la tuberculosis. La Palabra. 6 ago 1920. Localizado en: Hemeroteca Mayor de la Biblioteca General San Martín, Mendoza, Argentina.

53. Diarios de sesiones de la Cámara de Diputados, sesión correspondiente al día 4 de noviembre de 1919. Localizado en: Archivo Legislativo de la Honorable Cámara de Senadores de la provincia de Mendoza. Mendoza, Argentina. Caja 474.

54. Diario de sesiones legislativas de la Cámara de Diputados, sesión correspondiente al día 23 de noviembre de 1923. Localizado en: Archivo Legislativo de la Honorable Cámara de Senadores de la provincia de Mendoza. Mendoza, Argentina. Caja 477.

55. Luis N. La vivienda popular: Discurso y políticas públicas en la Mendoza lencinista (1918-1928). Cuadernos de Historia del Arte. 2018;30:27-96.

56. Rodríguez Vázquez F, Raffa C, (coords.). Profesionalizando un Estado provincial: Mendoza, 18901955. Mendoza: Universidad Nacional de Cuyo, Secretaría de Ciencia, Técnica y Posgrado; 2016.

57. Raffa C. Políticas sanitarias y arquitectura de Estado en Mendoza: el Gran Policlínico Central (1938-1943). Estudios Sociales del Estado. 2019. En prensa.

58. Hirschegger I. La Escuela Mixta de Enfermeros de 1942: una apuesta a la profesionalización de la enfermería en Mendoza. Trabajos y Comunicaciones. 2019;(49):e084. doi: $10.24215 / 23468971 \mathrm{e} 084$.

59. Hirschegger I. La Salud Pública frente a un Estado centralizado: establecimientos y servicios asistenciales en la provincia de Mendoza durante el primer peronismo. Trabajos y Comunicaciones. 2016;(44):e026. 
60. Suárez L. Memoria presentada a la Honorable Legislatura por el ministro de Industrias y Obras Públicas Ingeniero Leopoldo Suárez: Año 19221923. Mendoza; 1924. Localizado en: Biblioteca de Autores Locales, Biblioteca Pública General San Martín, Mendoza, Argentina.

61. Mendoza conmemora la fausta fecha del 25 de mayo, inaugurando el soberbio Hospital José Néstor Lencinas, magna obra iniciada por el gran ex - mandatario y que su hijo, el actual gobernador doctor Carlos W. Lencinas, ha llevado a feliz término. La Palabra, 23 may. 1924:1-8. Localizado en: Hemeroteca Mayor de la Biblioteca General San Martín, Mendoza, Argentina.

62. Di Liscia MS. Itinerarios curativos: Saberes, terapias y prácticas médicas indígenas, populares y científicas (Región Pampeana, 1750-1910). [Tesis de doctorado]. Instituto Universitario Ortega y Gasset, Facultad de Geografía e Historia, Universidad Complutense de Madrid; 2000.

63. Municipalidad de la Ciudad de Mendoza. Memoria presentada a la Honorable Corporación Municipal por el presidente Manuel A. Ceretti, desde $1^{\circ}$ de enero de 1901 a 31 de diciembre de 1902 . Mendoza: Tipografía Antigua Casa Mickes; 1903.

64. La reforma de la ley sanitaria. Los Andes, $21 \mathrm{dic}$ 1926. Localizado en: Hemeroteca Mayor de la Biblioteca General San Martín, Mendoza, Argentina.

65. González Leandri R. Itinerarios de la profesión médica y sus saberes de Estado: Buenos Aires, 1850-1910. En: Ben Plotkin M, Zimmermann E. Los saberes del Estado: Construcción de elites técnicas estatales en la Argentina, siglos XIX y XX. Buenos Aires: Edhasa; 2012.

66. Armus D. El descubrimiento de la enfermedad como problema social. En: Lobato M, (dir.). El Progreso, la modernización y sus límites (1880-1916). Buenos Aires: Sudamericana; 2000.

67. Armus D. "Milonguitas" en Buenos Aires (19101940): tanto, ascenso social y tuberculosis. História, Ciências, Saúde-Manguinhos. 2002;9(Supl):S187S207.
68. Armus D. La ciudad impura: Salud, tuberculosis y cultura en Buenos Aires, 1870-1950. Buenos Aires: Edhasa; 2007.

69. Carbonetti A. Cólera y conflicto en la ciudad de Córdoba, Argentina (1867-1868). Boletín Mexicano de Historia y Filosofía de la Medicina. 2007; 10:71-78.

70. Carbonetti A. Historia de una epidemia olvidada: La pandemia de gripe española en la Argentina, 1918-1919. Desacatos. 2010;32:159-174.

71. Carbonetti A. La ciudad de la peste blanca: Historia epidemiológica, política y cultural de la tuberculosis en la ciudad de Córdoba, Argentina. 1895-1947. México: Dirección de Fomento; 2011.

72. Álvarez A. El rol de los lazaretos en el control del cólera y la fiebre amarilla. Buenos Aires (18701915). História Revista. 2004;9:287-317.

73. Álvarez A. De la higiene pública a la higiene social en Buenos Aires, una mirada a través de sus protagonistas, 1880-1914. Boletín Mexicano de Historia y Filosofía de la Medicina. 2007;10:4-11.

74. Álvarez A. La aparición del cólera en Buenos Aires (Argentina), 1865-1996. Historelo. 2012;4(8): 172-208.

75. Di Liscia MS. Itinerarios curativos: Saberes, terapias y prácticas médicas indígenas, populares y científicas (Región Pampeana, 1750-1910). [Tesis de doctorado]. España: Facultad de Geografía e Historia, Universidad Complutense de Madrid; 2000.

76. Di Liscia MS. Robar el paraíso. Indios, viruela y bautismo en Argentina (1870-1884). Quinto Sol. 2000;(4):67-86.

77. Luis N. La alpargata en el espacio público: Los efectos de la política lencinista en el espacio público mendocino. [Tesis de doctorado]. Ciudad de Mendoza: Facultad de filosofía y Letras, Universidad Nacional de Cuyo; 2018.

Recibido: 19 dic 2018 | Versión final: 6 dic 2019 | Aprobado: 18 feb 2020| Publicado en línea: 6 abr 2020 